\title{
The Presentation of Adhesive Capsulitis of the Hip: A Case Study
}

Patrick E. Jurewicz, MS, SCAT, ATC*; Ryan C. Berlinrut, PA-C†; Frank K. Noojin III, MD;; Zachary K. Winkelmann, PhD, SCAT, ATC*

*University of South Carolina, Colombia, SC; †Prisma Health Orthopedics, Lexington, SC

\section{Full Citation}

Jurewicz PE, Berlinrut RC, Noojin FK, Winkelmann ZK. The Presentation of Adhesive Capsulitis of the Hip: A Case Study. Clin Pract Athl Train. $2021 ; 4(1):$ 64-65. https://doi.org/10.31622/2021/0004.1.10.

Presented at the $4^{\text {rd }}$ Annual Athletic Trainers in the Physician Practice Society Meeting and Conference, February 26-27, 2021.

\section{ABSTRACT}

A 47-year-old female patient employed as a nurse in a mental health facility working 10-hour shifts reported to the sports medicine clinic for an initial orthopaedic examination after she twisted and fell out of bed causing direct compressive forces on her right hip. She has a history of an underdeveloped right hip, a non-steroidal antiinflammatory drug (NSAID) allergy, and low back pain (Oswestry score: $41 / 50$, NPRS: $8 / 10$ ) and is classified as a heavy smoker for 30 years.

After initial onset, the patient's pain increased with all motions. The patient also described a 'catching sensation' in her hip. The patient used crutches for one month until her pain was intolerable, and she began to utilize a wheelchair to ambulate for daily activities. The differential diagnoses included acetabular labrum tear and ASIS tendonitis with additional considerations given to iliac spine avulsion fracture and lumbar radiculopathy. The initial examination included $x$ ray which showed no abnormalities and a magnetic resonance imaging scan which identified ASIS tendonitis with a possible symptomatic acetabular labrum tear. The patient's last full day of work was December 31 st, 2019.

Due to past medical history, the traditional management of NSAID use was ruled out and this patient was prescribed other pain medications. In addition, other interventions included an ultrasound guided intra-articular corticosteroid injection (CSI) and physical therapy with no positive response from the patient, however, minor relief was noted with oral steroid use. Preoperative blood work showed elevated levels of inflammatory markers, prompting a rheumatology referral. Patient reported feelings of anxiety, emotional stress, and depression on her health history questionnaire after three months of pain. The sports medicine clinic healthcare team ordered surgery of the acetabular labrum tear, which was delayed for five months due to the COVID-19 pandemic.

The patient's increasing pain and decreased ambulatory status forced her to remain out of work for the totality of the case presentation which spanned 8 months. Finally, in August 2020, an arthroscopy of her right hip was completed which confirmed a final diagnosis of an acetabular labrum tear and adhesive capsulitis of the right hip $(\mathrm{ACH})$. Post-surgery, the patient reported that her pain is improving and that she can ambulate using crutches.

Adhesive capsulitis of the hip (ACH) is an extremely rare clinical diagnosis with very little literature written on the topic. Currently there are no specific special tests for the identification of $\mathrm{ACH}$. However, ACH can present with similar indications as adhesive capsulitis of the shoulder such as chronic onset, decreased and painful ranges of motion, and synovial inflammation. Due to the uncommon nature of this ailment, traditional differential diagnoses are ruled out prior to consideration of $\mathrm{ACH}$ using diagnostic imaging. Traditional management of $\mathrm{ACH}$ includes oral anti-inflammatories, CSI, and physical therapy. 
Once other pathologies are ruled out, arthroscopy can be performed to confirm the presence of $\mathrm{ACH}$ which is similar to this case presentation. Providers should consider $\mathrm{ACH}$ when a patient presents with hip pain that is non-specific in terms of mechanism of injury, inflammatory markers, and pain location.

\section{Correspondence}

Patrick E Jurewicz, University of South Carolina, 1300 Wheat

St, Columbia, SC 29208

Email: jurewicp@email.sc.edu 